\title{
Regulatory Requirements and Registration Procedure for Generic Drugs in USA
}

\author{
Naziya Rafi, Sandeep DS*, Anoop Narayanan V \\ Department of Regulatory affairs, NITTE (Deemed to be university), NGSM Institute of Pharmaceutical Sciences, Paneer, Deralakatte, \\ Mangalore, Karnataka, INDIA.
}

\begin{abstract}
A generic drug is more efficient, safe and low-cost alternative of the innovator or branded drug in the market. They are similar to the branded drugs in strength, quality, purity and their safety and efficacy have been proven since they have been in the market for a longer time. The availability of generic medicine should be made easier throughout the world. The US has one of the most demanding regulatory authorities and registration of drug products will be a long process if not complied with the US Food and Drug Administration (USFDA) guidelines. Abbreviated New Drug Application is the application to be filed for registering generic drug. One of the main tasks of the regulatory authorities is to ensure that the drug development, manufacture and testing has been carried out according to the regulations and guidelines and that everything is documented accordingly. International Conference on Harmonization (ICH) established a harmonized format for submission of application on registering drug products. This paper approaches the registration requirements of generic drugs in the form a dossier for market authorization in the US.
\end{abstract}

Key words: Generic drugs, Common technical document, ANDA, USFDA.

\section{INTRODUCTION}

A generic drug is a drug defined as "a drug product that is comparable to a brand/ reference listed drug product in dosage form, strength, quality and performance characteristics and intended use". Any drug that is marketed by its chemical name rather than advertising its brand name or chemical make-up is referred to as a generic drug. Even though they are not under any particular company they are subjected to regulation by the authorities of the government of that country. ${ }^{1}$

The original formulation and the generic drug should contain the same active ingredients. The Generic drug should be bioequivalent to the brand or innovator drug and the rate or the extent of active ingredient delivered to the systemic circulation should be the same.

The US Food and Drug Administration (FDA) considers a generic drug to be "identical, or bioequivalent, to a brand name drug in dosage form, safety, strength, route of administration, quality, performance characteristics and intended use". ${ }^{1-2}$

The Generic drug comes into the market once the patent ends or patent owner waives his rights and the FDA requirements are met. Once the generic drug becomes available, the market competition is increased hence the prices of both generic and the original brand is lowered. Generic drugs are usually sold at the much lower price compared to the original brand drug.

Clinical data on the safety and efficacy of the drug is not required to be submitted in the case of generic drugs because it has been already provided for the prior product. The safety and efficacy of the original active ingredient was already proven, the bioequivalence of the equivalent generic drug should be checked by the manufacturer. ${ }^{3}$
Submission Date: 02-03-2018; Revision Date: 13-04-2018; Accepted Date: 17-05-2018

DOI: 10.5530/ijper.52.4.63 Correspondence: Sandeep DS,

Assistant Professor, Department of Regulatory Affairs, NGSM institute of Pharmaceutical Sciences, NITTE (Deemed to be university) Paneer, Deralakatte, Manglore-575018, Karnataka, INDIA. Phone: +919036717475 E-mail: sandypharama@ gmail.com

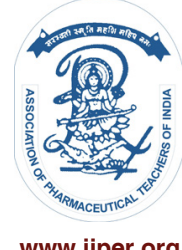

www.ijper.org 


\section{US FOOD AND DRUG ADMINISTRATION (USFDA)}

The USFDA is a scientific, regulatory and public health agency that jurisdiction encompasses on most food products (other than meat and poultry), human and animal drugs, therapeutic agents of biological origin, medicinal devices, radiation-emitting products for consumer, medical occupational use, cosmetics and animal feed. The Office of the Commissioner heads the organization under which there are four departments overlooking management, health, and science, international activities and regulatory affairs. They have various centers for regulation of medicinal products, medical devices, food, veterinary products and also toxicological research. The organizational structure of the USFDA is shown in Figure 1.

The FDA is also responsible for advancing the public health by helping to spend innovations that make medicines and food more effective, safer, more affordable and helping the public to get proper, scientific information about the food and medicines to improve their health. ${ }^{4}$

\section{ABBREVIATED NEW DRUG APPLICATION (ANDA)}

The Documents or the application submitted to the FDA for the approval of a generic drug product is known as an Abbreviated New Drug Application or ANDA. It contains all the data for FDA review and approval.

Once the ANDA is approved the manufacturer can market the safe, effective and less expensive generic version. Generic drug applications are referred to as "abbreviated" because they are not required to submit any clinical and animal studies to prove their safety and efficacy. The generic drugs are scientifically proven to be having the same properties to that of the innovator drug. To demonstrate that a generic drug is similar to the innovator drug is to measure the bioavailability of the drug in the systemic circulation of healthy volunteers. Bioavailability, the rate of absorption of the generic

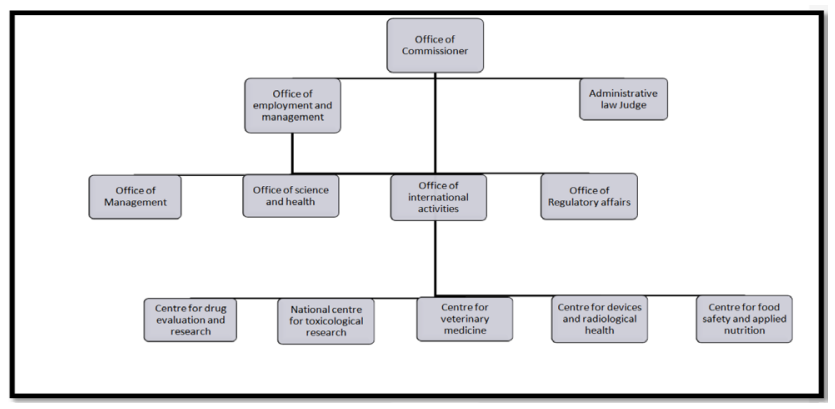

Figure 1: Organization chart of the US food and drug administration. drug is evaluated by conducting 'Bioequivalence' study and is compared to the branded drug. To be approved by FDA, the amount of active ingredients in the circulatory system of the patient should be same for both the generic and the innovator drug. Enactment of the Drug Price Competition and Patent Restoration Act of 1984, better known as "The Hatch- Waxman Act" is the major force for generic market development in the US. It has created opportunities for developing and marketing generics or better called an abbreviated new drug application for 180 days. Final approval of ANDA by the FDA takes minimum18 months. Under ANDAs a pharmaceutical manufacturer can develop and market low price generic version of previously approved innovator drugs, thus providing the same product to a patient in pregnable price with safety and efficacy all approved products, both innovator, and generics, are enlisted in FDA's orange book. ${ }^{5}$

\section{Types of certifications}

The generic makes one of four certifications for each patent:

Paragraph (I): That no patent information on that brand name drug has been submitted to the FDA.

Paragraph (II): That the listed patent has expired.

Paragraph (III): That the listed patent will expire on a certain date, before which time the generic will not enter the market.

Paragraph (IV): That the patent is invalid or will not be infringed by the manufacture, use, or sale of the new drug for which the ANDA was submitted.

When the generic makes a paragraph I or II certification, the FDA may approve its ANDA immediately. The FDA may approve a paragraph III certification any time after the patent's expiration date. The implications of a paragraph IV certification are not nearly as simple. A generic makes a paragraph IV certification when it does not want to wait for the expiration of the pioneer's patent rights before it begins to market its own generic version of the drug. Instead, it alleges that it is justified in early market entry because its drug does not infringe the pioneer's patent or because the patent is invalid..$^{6-7}$

\section{Common Technical Document (CTD)}

CTD is a common technical document, it is a harmonized document introduced by the ICH in order to avoid any duplication and easier translation into regional languages in a single application. CTD makes it easier to submit one single application to more than one country at the same time for registration of the drug product. According to $\mathrm{ICH}$, all the technical requirements for the application of drug approval were harmonized in CTD 
format which is scientifically more elaborate by USFDA in Quality Overall Summary (QOS) and Overall efficacy (includes a clinical overview and clinical summary). This has improved the presentation of the registration documents has expedited the efficiency in the FDA review process. $^{7}$

The main Areas of Harmonization for CTD are:

- Safety pharmacology

- Clinical pathology

- Immunotoxicology

- Juvenile toxicology studies

- Statistical methods in certain studies like mutagenicity, carcinogenicity and toxicokinetic studies during

The Common Technical Document is organized into five modules. The contents of Module 1 are different according to the competent authorities' of the United States (FDA), the European Agency for the Evaluation of Medicinal products (EU). The modules are present in the triangular format which all the modules are the part of CTD. Module 1 is not the part of CTD it is different for different countries. The different modules are as follows:

Module 1: This module is specific to each region and is usually not part of the CTD. It contains all the administrative information and prescribing information (package inserts and labeling) with respect to the regulatory agency of that particular country.

Module 2: It consists of the overviews and overall summaries of the CTD. Quality overall summaries, clinical and non-clinical overview and summaries are included in this module. Pharmacology, pharmacokinetics, toxicology studies which are important to prove the safety and efficacy of the drug.

Module 3: Quality - It covers the complete pharmaceutical and technical aspects which can affect the quality of the drug product. From the formulation and development department (pharmaceutical development report) to the manufacturing (GMP), analysis and testing (GLP), packing, storage conditions, stability studies of the product.

Module 4: Non-clinical study reports - It covers the complete pharmacological, toxicological study reports and information equivalent to the quality of the drug to provide the evidence of the safety of the drug product. Module 5: Clinical study Reports - The results of various clinical trials on human beings and the reports listing the desired effect of the drug product are mentioned in this part. This part proves the efficacy of the drug to the regulatory authorities. Bioequivalence studies are conducted on healthy volunteers to prove

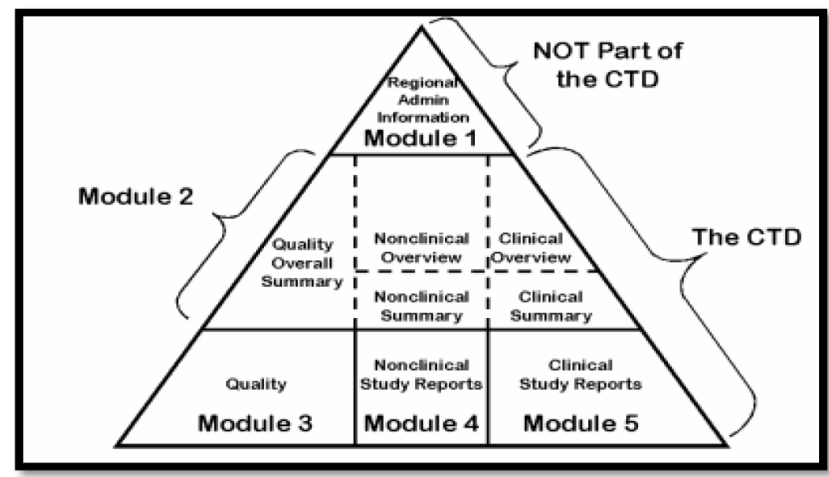

Figure 2: CTD triangle.

the bioavailability similarity between the both generic and innovator drugs. ${ }^{8}$

Before CTD/eCTD application for the submission of a drug application, the procedure was different as per the country wise. In US, NDA, ANDA, BLA, Integrated summary of safety (ISS), integrated summary of Efficacy (ISE) was submitted for the approval of the product as shown in the figure, so many duplicate copies were required to be made according to the FDA. The various modules of the CTD are shown in the triangle format in Figure 2.

\section{Generic Drug Product Registration Requirements in the US}

1. The eCTD is mandatory for the submission of the drug applications (NDA/ANDA).

2. US FDA guidance (CFR) documents and FDA sections (e.g. 505 (b) for NDA and 505(j) for ANDA) are followed for the preparation of the dossier for the drug approval applications.

3. The applications are different as follows:

- For new drug- NDA

- For generic drug-ANDA

- For biological application - BLA

4. The applicant himself or a GDEA (Generic Drug Enforcement Act) certified and approved agent may directly submit the application to the FDA.

5. Administrative information is different from a cover letter, forms (356h), application information, field copy certification, debarment certification, financial certification, Patent information, and exclusivity.

6. The paper size for the submission is Letter size ( $8.5 \times 11$ inches) with font size 12 in times new roman format. The tables and figures have small font size i.e. 8 to 10 .

7. Package inserts are provided for drug product in labeling. 
8. Proposed Labels and cartons with proper dimensions similar to that of the RLD (Reference Listed Drugs) labels are provided.

9. The information about the clinical investigators is provided in Module 5 and in financial disclosure Statement section of this module.

10. Request for waiver of in-vivo $\mathrm{BE}$ studies is provided in module 1.

11. Annotated draft labeling (side by side) for labels and cartons compared with the RLD with proper annotation is provided.

12. The EAS (Environment Assessment Statement) for categorical exclusion certification in compliance with the law of EPA (Environment Protection Act) of US is provided.

13. Risk management Plans section is for the postmarketing surveillance and controlling the adverse effects of the drugs by proper management. This is the part of Clinical Trial Phase IV.

14. The declaration is given for the residual solvents limits used or present in the drug substance and excipients according to the USP.

15. Information on components including the name and address of the supplier or manufacturer of the raw material, package material etc. provided in the 3.2.R format.

16. Certificate of suitability (CEP certificate) is not applicable.

17. Comparability protocols are not attached to both the drug substance and drug products.

18. The stability data for accelerated studies are submitted for three months at the time of original submission.

19. Structured product labeling (SPL) and study tagging file (STF) is mandatory by the USFDA in eCTD of a drug registration application. ${ }^{9-10}$

\section{ANDA Regulatory Review Process}

The ANDA process begins when an applicant submits an ANDA to the OGD (Office Generic Drugs) or CDER (Centre for Drug Evaluation and Research). The document room staff process the ANDA assigns it an ANDA number, and stamps a received date on the cover letter of the ANDA. The ANDA is then sent to a consumer safety technician, who reviews the preliminary sections of the ANDA checklist. The submitted ANDA is reviewed taking into consideration bioequivalence of the drug, chemistry and microbiology, and also the labeling. Within the first 60 days following the submission of an ANDA, a filing review is completed. ${ }^{11-12}$ The

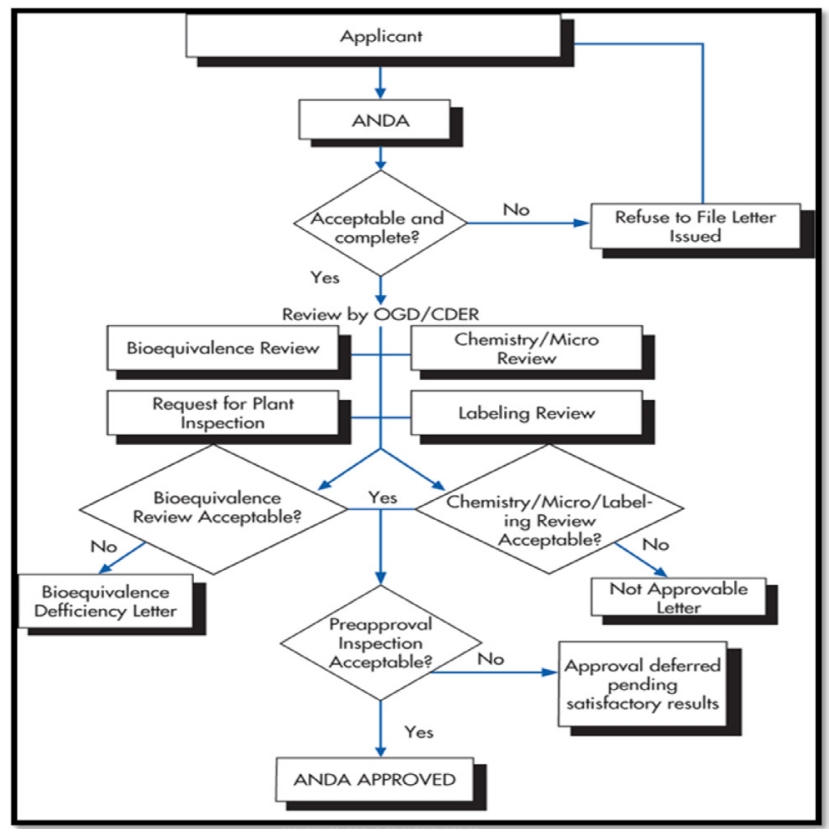

Figure 3: ANDA Review Process.

ANDA regulatory review process of USFDA is simplified as a flowchart in Figure 3.

\section{Bio Equivalence Review Process}

The two main characteristics of a generic drug to be therapeutically equivalent to the innovator drug are to be pharmaceutically equivalent and also bioequivalent. Both the innovator and generic drug should be pharmaceutically equivalent i.e. they should have the same strength, dosage form and same route of administration. The products are said to be bioequivalent when they have similar bioavailability when they are studied under same conditions. ${ }^{13}$

Bioequivalence is determined by evaluation of the AUC and the maximum concentration of drug $\left(\mathrm{C}_{\max }\right)$. A generic product is considered to be bioequivalent to the branded product if the $90 \%$ confidence interval (CI) of the mean AUC and the relative mean $\mathrm{C}_{\max }$ is $80 \%$ to $125 \%$.

\section{Labeling Review Process}

The labeling review process is to ensure that both the innovator and the generic drug have the same labeling. After the final level administrative review and individual disciplines have resolved their deficiencies, the application will either receive a full approval or a tentative approval letter. A full approval letter details the conditions of approval and allows the applicant to market the generic drug product. A tentative approval letter is issued if there are unexpired patents or exclusivities accorded to the Reference Listed Drug (RLD). ${ }^{14}$ 


\section{CONCLUSION}

The United States has the most stringent regulation for generic drug filing in the world. The regulatory authorities should ensure that the pharmaceutical companies comply with the FDA regulations and guidelines. There are regulations and guidelines that help in drug development, manufacture, and safety testing so that they are safe and efficient and do not harm the patient's well-being. CTD provides a globally harmonized format that is accepted in many regions, avoiding the need to compile different registration dossiers for different regulatory authorities. The primary purpose of the rules governing medicinal products in the US is to check whether drugs are manufactured in accordance to the guidelines so that they are safe and patient's well-being is protected. Countries have different standards; there are high registration costs and long timelines for registration of generic drugs. This may account for the good market share of generics in the USA.

\section{ACKNOWLEDGEMENT}

The authors are thankful to the principal and management of NGSM Institute of Pharmaceutical Sciences for their support and encouragement in writing this review.

\section{CONFLICT OF INTEREST}

The authors declare no conflict of interest.

\section{ABBREVIATIONS}

USFDA: United States Food and Drug Administration; CTD: Common technical document; ANDA: Abbreviated new drug Application; NDA: New Drug Application; GMP: Good Manufacturing Practices; GDEA: Generic Drug Enforcement Act; QOS: Qual- ity overall summary; EU: European Union; CFR: Code of Federal Regulations; RLD: Reference listed drugs; EAS: Environment assessment statement; EPA: Environment protection act; OGD: Office generic drugs; CDER: Centre for drug evaluation and research; AUC: Area Under the Curve.

\section{REFERENCES}

1. United States Food and Drug Administration. Available from: http://www.fda. gov/AboutFDA/CentersOffices/de fault.html [accessed 13.11. 2017].

2. Dylst $P$, Vulto $A$, Simoens $S$. Overcoming challenges in market access of generic medicines in the European Union. Journal of Generic Medicines. 2012;9(1):21-8.

3. Hassali $\mathrm{M}$ et al. Physicians' views on generic medicines: a narrative review. Journal of Generic Medicines. 2010;7(1):30-9.

4. "Generic Drugs", U.S. Food and Drug Administration. Available from: http://en.wikipedia.org/wiki/U.S._Food_and_Drug_Administration [accessed23.11.2017].

5. Generic drug. Availablefrom:http://en.wikipedia.org/wiki/Generic_drug\#cite_ note-0. [Accessed 28.11. 2017].

6. Abbreviated New Drug Application (ANDA): Generics.Availablefrom:http:// www.fda.gov/Drugs/DevelopmentApprovalProcess/HowDrugsareDeveloped and Approved/Approval Applications/Abbreviated New Drug Application ANDA Generics. [Accessed 28.11.17].

7. Guideline on submission of documentation for a multisource (generic) finished pharmaceutical product (FPP): Preparation of product dossiers (PDS) in common technical document (CTD) format. 2017.

8. Guideline on submission of documentation for a multisource (generic) finished pharmaceutical product (FPP): Preparation of product dossiers (PDS) in common technical document (CTD) format. 2018.

9. Rahul R, et al. Comparative Study of Generic Drug Approval in EU, USA and China. Int J Pharm Sci Rev Res. 2017;42(2):67-73.

10. Ramana MV, et al. Generic Drug Registration Procedure in US and European Markets. Am J Pharm Health Res. 2014;2(11):12-21.

11. Kashyap NU, et al. Comparison of Drug Approval Process in United States and Eur. J Pharm Sci Res. 2013;5(6):131-6.

12. Venkateswarlu $B$, et al. Regulatory Requirements for the registration of generic solid oral in USA, Singapore, Malaysia and Thailand. Journal of global trends in pharmaceutical sciences. 2014;5(4):2225-32.

13. Swain S, Dey A, Patra CN, Bhanoji Rao ME. Pharma Regulations for Generic Drug Products in India and US: Case Studies and Future Prospectives. Pharmaceut Reg Affairs. 2014;3(119):1-6.

14. Abbreviated New Drug Application (ANDA) approval process. Available from: http://fdadrugcompliance.com/resources/anda/[accessed 30.11.17]. 


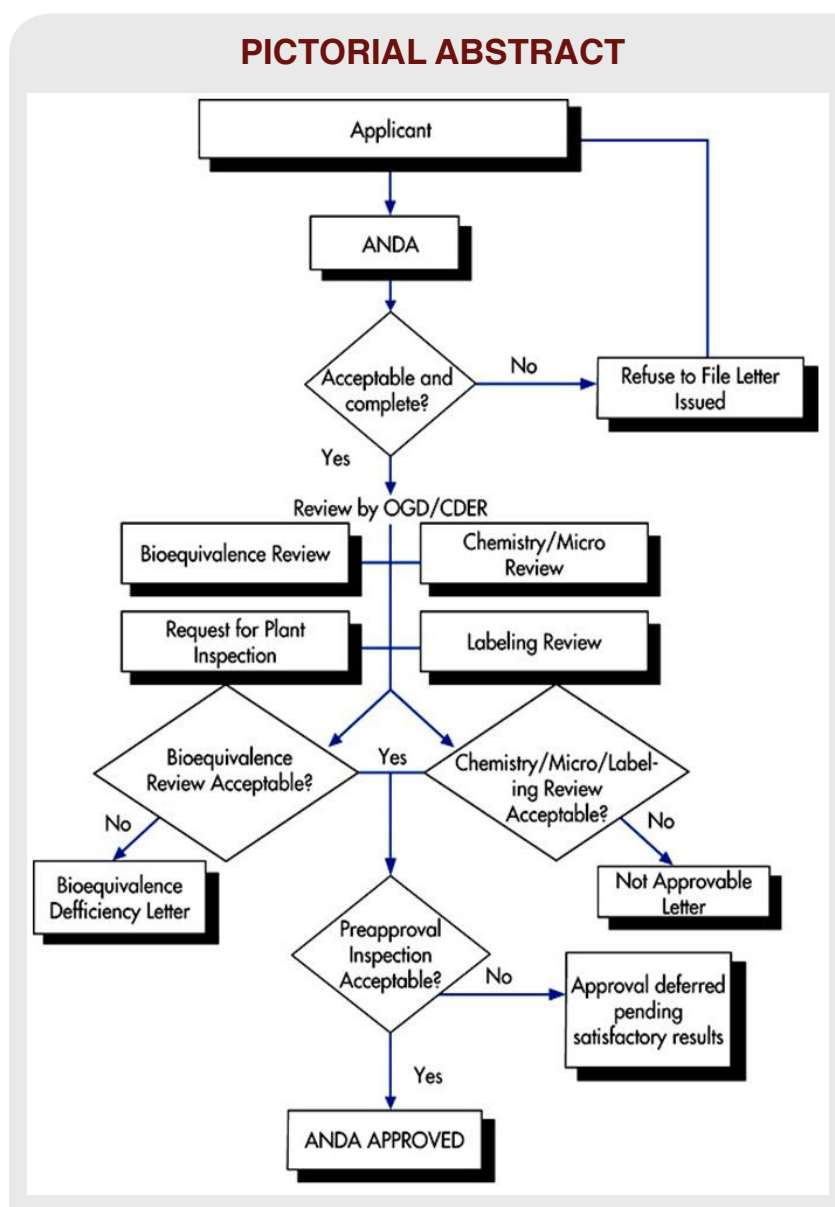

\section{SUMMARY}

- The United States has the most stringent regulation for generic drug filing in the world. The application submitted to the FDA for the approval of a generic drug product is known as an Abbreviated New Drug Application or ANDA. It contains all the data for FDA review and approval. CTD makes it easier to submit one single application to more than one country at the same time for registration of the drug product. The Common Technical Document is organized into five modules like company information, quality summary, non-clinical and clinical overview and their reports. ANDA review process include the review of regulatory aspects, bioequivalence, labelling saspects.

\section{About Authors}

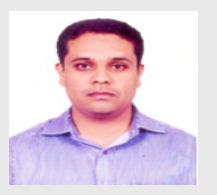

Mr. Sandeep DS: Is currently working as Assistant Professor, Department of Pharmaceutics at N.G.S.M Institute of Pharmaceutical Sciences, Nitte (Deemed to be university). He has 2 years of industrial experience and 4 years of teaching experience. His area of interest includes Regulatory aspects of Pharmaceuticals, Formulation development of ocular drug delivery systems and Nano formulations. 